\title{
Drought Tolerance Responses in Vegetable-Type Soybean Involve a Network of Biochemical Mechanisms at Flowering and Pod-Filling Stages
}

\author{
Makoena Joyce Moloi ${ }^{1, *(D)}$ and Rouxlene van der Merwe ${ }^{2}$ (D) \\ 1 Department of Plant Sciences-Botany Division, University of the Free State, 205 Nelson Mandela Drive, Park \\ West, Bloemfontein 9301, South Africa \\ 2 Department of Plant Sciences-Plant Breeding Division, University of the Free State, 205 Nelson Mandela \\ Drive, Park West, Bloemfontein 9301, South Africa; vandermerwer@ufs.ac.za \\ * Correspondence: moloimj@ufs.ac.za; Tel.: +27-51-401-9483
}

check for updates

Citation: Moloi, M.J.; van der Merwe, R. Drought Tolerance Responses in Vegetable-Type Soybean Involve a Network of Biochemical Mechanisms at Flowering and Pod-Filling Stages. Plants 2021, 10, 1502. https:// doi.org/10.3390/plants10081502

Academic Editor: Josefa M. Alamillo

Received: 27 May 2021

Accepted: 22 June 2021

Published: 22 July 2021

Publisher's Note: MDPI stays neutral with regard to jurisdictional claims in published maps and institutional affiliations.

Copyright: (c) 2021 by the authors. Licensee MDPI, Basel, Switzerland. This article is an open access article distributed under the terms and conditions of the Creative Commons Attribution (CC BY) license (https:/ / creativecommons.org/licenses/by/ $4.0 /)$.

\begin{abstract}
Severe drought stress affects the production of vegetable-type soybean (Glycine max L. Merrill), which is in infancy for Africa despite its huge nutritional benefits. This study was conducted under controlled environmental conditions to establish the effects of severe drought stress on ascorbate peroxidase (APX), guaiacol peroxidase (GPX), and glutathione reductase (GR) activities as well as proline, total soluble sugars (TSS), and hydrogen peroxide $\left(\mathrm{H}_{2} \mathrm{O}_{2}\right)$ contents of five vegetable-type soybean cultivars (UVE8, UVE14, UVE17, AGS354, AGS429) at flowering and pod-filling stages. Drought induced significant increases in the contents of proline (selectively at pod filling for AGS429), TSS (at both stages for AGS429, and only at pod filling for UVE14), and malondialdehyde (AGS354 at flowering; UVE17 at pod filling). UVE8 and AGS354 had the highest $\mathrm{H}_{2} \mathrm{O}_{2}$ levels at flowering under drought stress, while AGS429 had the lowest. However, AGS429 was the only cultivar with significantly increased $\mathrm{H}_{2} \mathrm{O}_{2}$ under drought stress. Furthermore, drought stress induced significant increases in APX, GPX, and GR activities at flowering for AGS429. AGS354 recorded the highest decline for all antioxidative enzymes, while UVE17 decreased for GPX only. All biochemical parameters, except $\mathrm{H}_{2} \mathrm{O}_{2}$, were significantly higher at pod filling than at the flowering stage. The relationship between $\mathrm{H}_{2} \mathrm{O}_{2}$ and total seed mass (TSMP) or total seed per plant (TSP) was significantly positive for both stages, while that of TSS (at flowering) and proline (at pod filling) were significantly related to total pods per plant (TPP). The study suggests that during drought, the tolerance responses of vegetable-type soybean, APX, GPX, and GR (especially at the flowering stage), function in concert to minimize $\mathrm{H}_{2} \mathrm{O}_{2}$ production and lipid peroxidation, thereby allowing $\mathrm{H}_{2} \mathrm{O}_{2}$ to function in the signaling events leading to the induction of drought tolerance. The induction of TSS at flowering and proline at pod filling is important in the drought tolerance response of this crop.
\end{abstract}

Keywords: antioxidative enzymes; edamame; Glycine max; hydrogen peroxide; lipid peroxidation; proline; total soluble sugars; water deficit

\section{Introduction}

Drought stress is a catalyst of great famines and is accelerated by anthropogenic climate changes [1]. Such stress negatively affects soybean production [2]. Vegetable-type soybean (Glycine max L. Merrill) is a complete protein food source (because it contains all eight essential amino acids) with numerous vitamins, minerals, isoflavones, fiber, magnesium, folate; it also lowers blood cholesterol [3]. Production of this crop in Africa is in its infancy despite its huge nutritional advantages. Only a few cultivars are produced by small-scale, resource-poor farmers [4]; these cultivars are not yet commercialized in South Africa. Since the crop is less popular, knowledge about its responses to extreme environmental conditions such as drought is inadequate. This deepens the threat of food security in Africa and other parts of the world [5]. 
The responses of plants to drought stress varies from species to species, depending on plant growth stage and other environmental factors [6]. Mild stress at the grain filling phase can substantially reduce crop yield. Other noticeable effects of drought stress include damage of the photosynthetic apparatus, membrane instability [7], and, consequently, death, which mainly result from oxidative stress caused by excessive production of reactive oxygen species (ROS) such as superoxide radicals and hydrogen peroxide [8]. Plants have evolved a number of biochemical and physiological mechanisms to improve their tolerance to abiotic stress. These may include the employment of various antioxidative mechanisms that are enzymatic or non-enzymatic in nature. Some antioxidative mechanisms include enzymes of the ascorbate-glutathione pathway, guaiacol peroxidase, catalase, and superoxide dismutase [9]. In addition, plants may also cope with drought stress by stimulating the production of osmolytes such as proline and non-structured sugars, which increase their osmotic potential [1].

Knowledge of the biochemical mechanisms for drought tolerance in vegetable-type soybeans is very limited. In order to improve the tolerance of this crop to drought, which is the ultimate goal, a better understanding of the physiological and biochemical mechanisms of drought tolerance is key because such information may be used for the selection of better-performing cultivars. Previous studies on grain soybean have suggested that yield can be associated with high proline accumulation under water limiting conditions [10]. Furthermore, a susceptible grain soybean cultivar with low proline content has corresponding low ascorbate peroxidase activity at both flowering and pod-filling stages [11]. However, no information is available on the biochemical responses of vegetable-type soybean cultivars used in this study. Therefore, this research aims to establish the important biochemical mechanisms of drought tolerance in vegetable-type soybean. The study was performed at flowering and pod-filling stages to determine if such biochemical responses would differ according to the developmental stages under drought stress in this crop. Additionally, the study provides information on the biochemical performance of the various cultivars under drought stress. Such information will accelerate vegetable-type soybean drought tolerance breeding, which will improve crop yield (tons per hectare) under severe drought stress.

\section{Results}

At the flowering stage, the cultivar effect was significant for all parameters except for proline. The water treatment effect was not significant for GPX, GR, and proline. Cultivar by treatment interaction was significant for the antioxidative enzymes and TSS. At pod filling, the cultivar effect was not significant for TSS, while the treatment effect was not significant for GR. Cultivar by treatment effect was significant for the antioxidative enzymes only (Table 1).

Table 1. Analysis of variance for the biochemical parameters of five vegetable-type soybean cultivars subjected to two water treatments at flowering and pod-filling stages.

\begin{tabular}{ccccccc}
\hline & \multicolumn{3}{c}{ Flowering } & & Pod Filling \\
\hline Variate & Cultivar (C) & Treatment (T) & $\mathbf{C} \times \mathbf{T}$ & Cultivar (C) & Treatment (T) & $\mathbf{C} \times \mathbf{T}$ \\
\hline $\mathrm{APX}$ & $0.000697^{* * *}$ & $0.000669^{* * *}$ & $0.000429^{* * *}$ & $0.111300^{* * *}$ & $0.2875^{* * *}$ & $0.146200^{* * *}$ \\
$\mathrm{GPX}$ & $0.174360^{* * *}$ & 0.026590 & $0.102130^{* * *}$ & $0.114200^{* * *}$ & $0.0447^{* * *}$ & $0.009780^{* * *}$ \\
$\mathrm{GR}$ & $0.193300^{* * *}$ & $0.063000^{* * *}$ & $0.127300^{* * *}$ & $0.331300^{* * *}$ & $0.000004^{*}$ & $0.041500^{*}$ \\
$\mathrm{H}_{2} \mathrm{O}_{2}$ & $4.675600^{* * *}$ & $1.548600^{* *}$ & 0.075900 & $0.051778^{* * *}$ & $0.082577^{* * *}$ & 0.006332 \\
$\mathrm{MDA}$ & $0.068490^{* * *}$ & $0.053066^{* *}$ & 0.002256 & $15.70900^{* *}$ & $53.027^{* * *}$ & 2.737000 \\
Proline & $0.025750^{* * *}$ & $0.006220^{* * *}$ & $0.102680^{* *}$ & $0.191190^{* * *}$ & $0.1627^{* * *}$ & 0.017870 \\
TSS & $1.768700^{* * *}$ & $2.189700^{* * *}$ & $0.188200^{*}$ & 0.256100 & $5.6472^{* * *}$ & 0.106800 \\
\hline
\end{tabular}

${ }^{*} p \leq 0.05,{ }^{* *} p \leq 0.01,{ }^{* * *} p \leq 0.001$. APX $=$ ascorbate peroxidase, GPX = guaiacol peroxidase, $\mathrm{GR}=$ glutathione reductase, $\mathrm{H}_{2} \mathrm{O}_{2}=$ hydrogen peroxide, $\mathrm{MDA}=$ malondialdehyde, and TSS $=$ total soluble sugars. 
At flowering, drought stress increased proline accumulation to higher levels in all cultivars with the exception of AGS354. However, such responses were not significant. Moreover, there was no distinction between the cultivars under drought stress treatment at the flowering stage. Although cultivars were not significantly different under drought stress (except for UVE8) at pod filling, proline increased to substantiated levels in AGS429 (2.25-fold). Proline was lower at flowering than at pod filling (Figure 1).

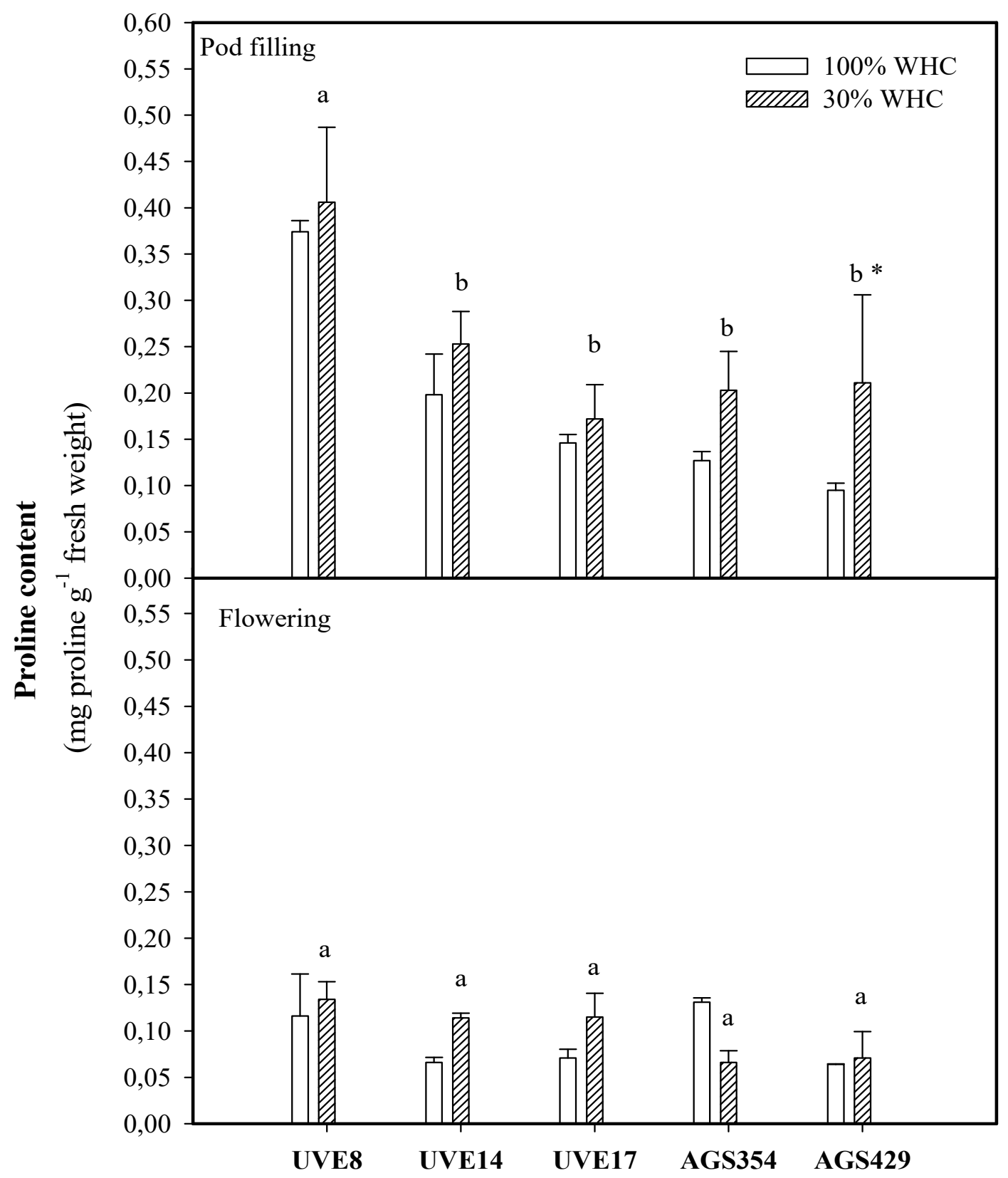

Figure 1. Proline content for five vegetable-type soybean cultivars subjected to two water treatments at flowering and pod filling stages. Values represent means $\pm \mathrm{SD}(n=3)$. Letters represent significant differences/similarities in proline content for various cultivars under severe water stress at $30 \%$ water holding capacity (WHC), ${ }^{*}$ represents significance at $p \leq 0.05$.

Drought stress induced TSS production at flowering, with the highest significant increase observed for AGS429 (1.75-fold). This cultivar was significantly different from others under drought stress at this stage. At pod filling, under drought stress, the cultivars were not significantly different. However, the increase in TSS production due to drought stress was significantly high in AGS429 (47\% increase) and UVE14 (49\% increase) compared 
to the controls. Higher TSS values were recorded at flowering compared to the pod-filling stage (Figure 2).

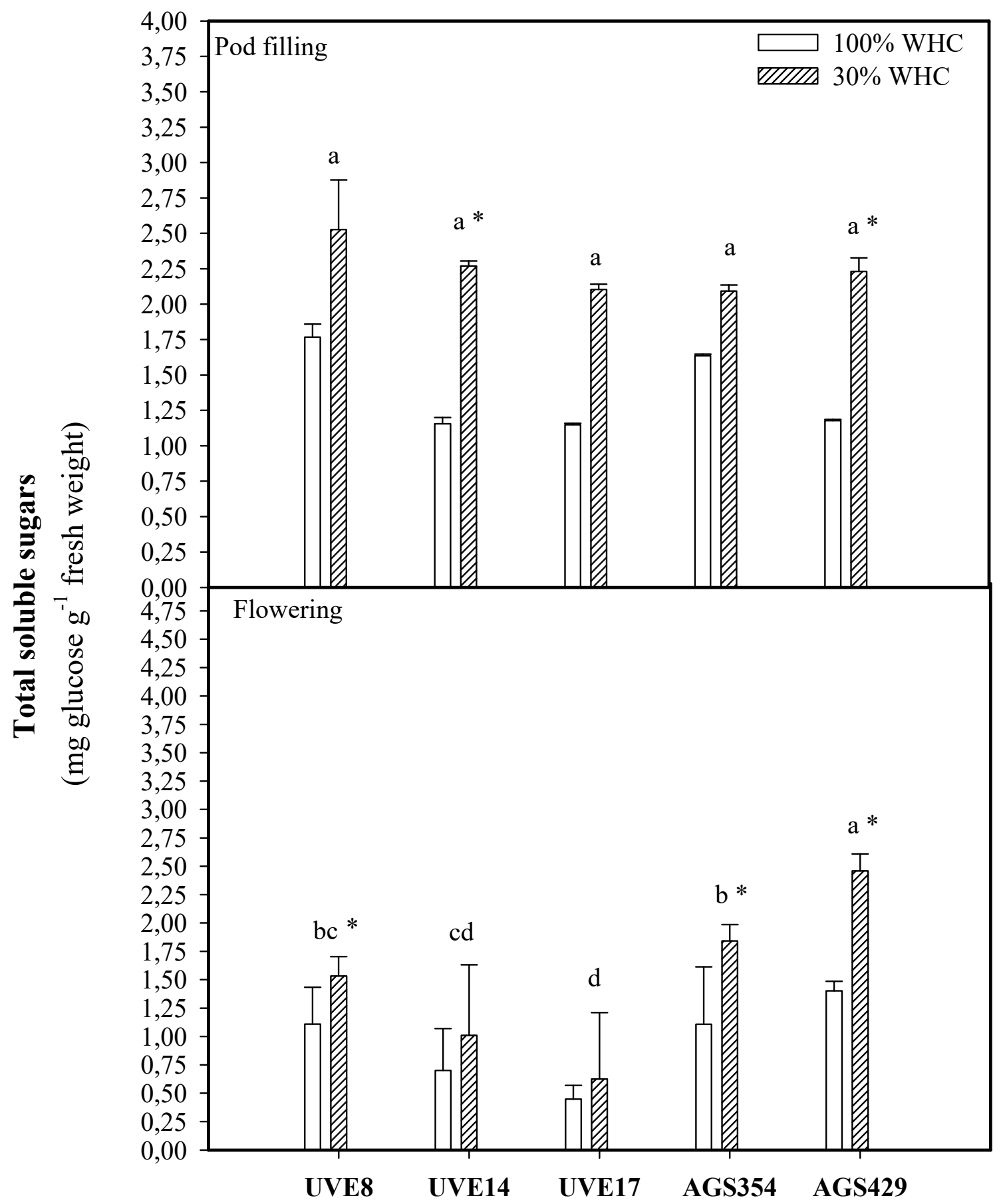

Figure 2. Total soluble sugar (TSS) content for five vegetable-type soybean cultivars subjected to two water treatments at flowering and pod-filling stages. Values represent means $\pm \operatorname{SD}(n=3)$. Letters represent significant differences/similarities in TSS content for various cultivars under severe water stress at $30 \%$ water holding capacity (WHC), ${ }^{*}$ represents significance at $p \leq 0.05$.

Malondialdehyde (MDA) content was not significantly different for all cultivars except AGS354 under drought stress at flowering. The highest and most significant increase in MDA production was observed in AGS354 (1.39-fold). At pod filling, a similar pattern was observed, where drought stress induced the production of MDA in all cultivars. However, UVE17 and UVE14 were the only two cultivars with significant increases in MDA (1.37-fold and 1.84-fold, respectively) compared to the control (Figure 3). 


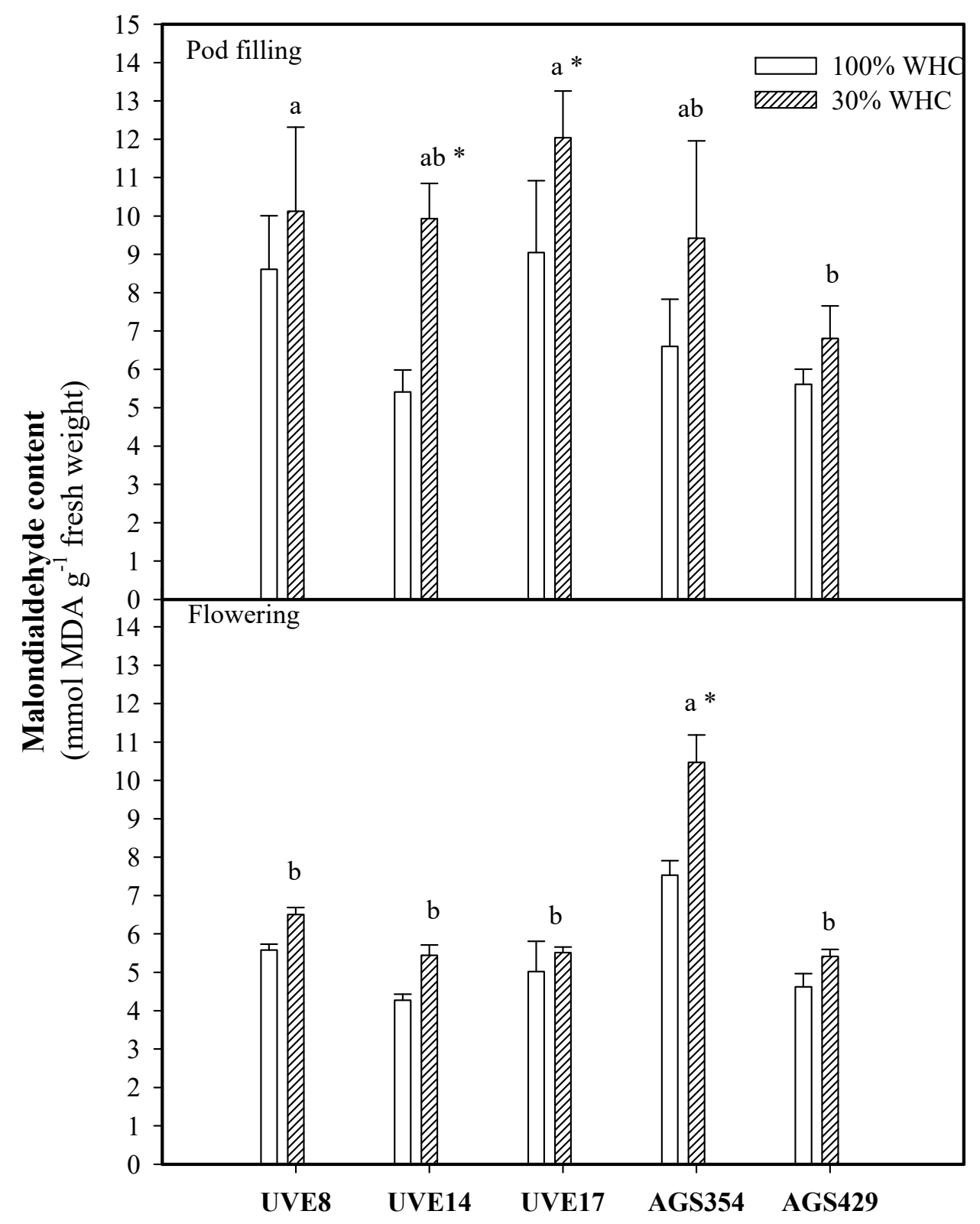

Figure 3. Malondialdehyde (MDA) content for five vegetable-type soybean cultivars subjected to two water treatments at flowering and pod-filling stages. Values represent means $\pm \mathrm{SD}(n=3)$. Letters represent significant differences/similarities in MDA content for various cultivars under severe water stress at $30 \%$ water holding capacity (WHC), * represents significance at $p \leq 0.05$.

Hydrogen peroxide content increased with drought stress irrespective of the growth stage except for UVE8 at the pod-filling stage. Although the level of $\mathrm{H}_{2} \mathrm{O}_{2}$ was low in AGS429, it was the only cultivar with significantly increased $\mathrm{H}_{2} \mathrm{O}_{2}$ (1.45-fold) compared to the control. Under drought stress at pod filling, UVE14 was the only cultivar that induced a substantial increase in $\mathrm{H}_{2} \mathrm{O}_{2}$ content (1.62-fold) compared to the control (Figure 4). 


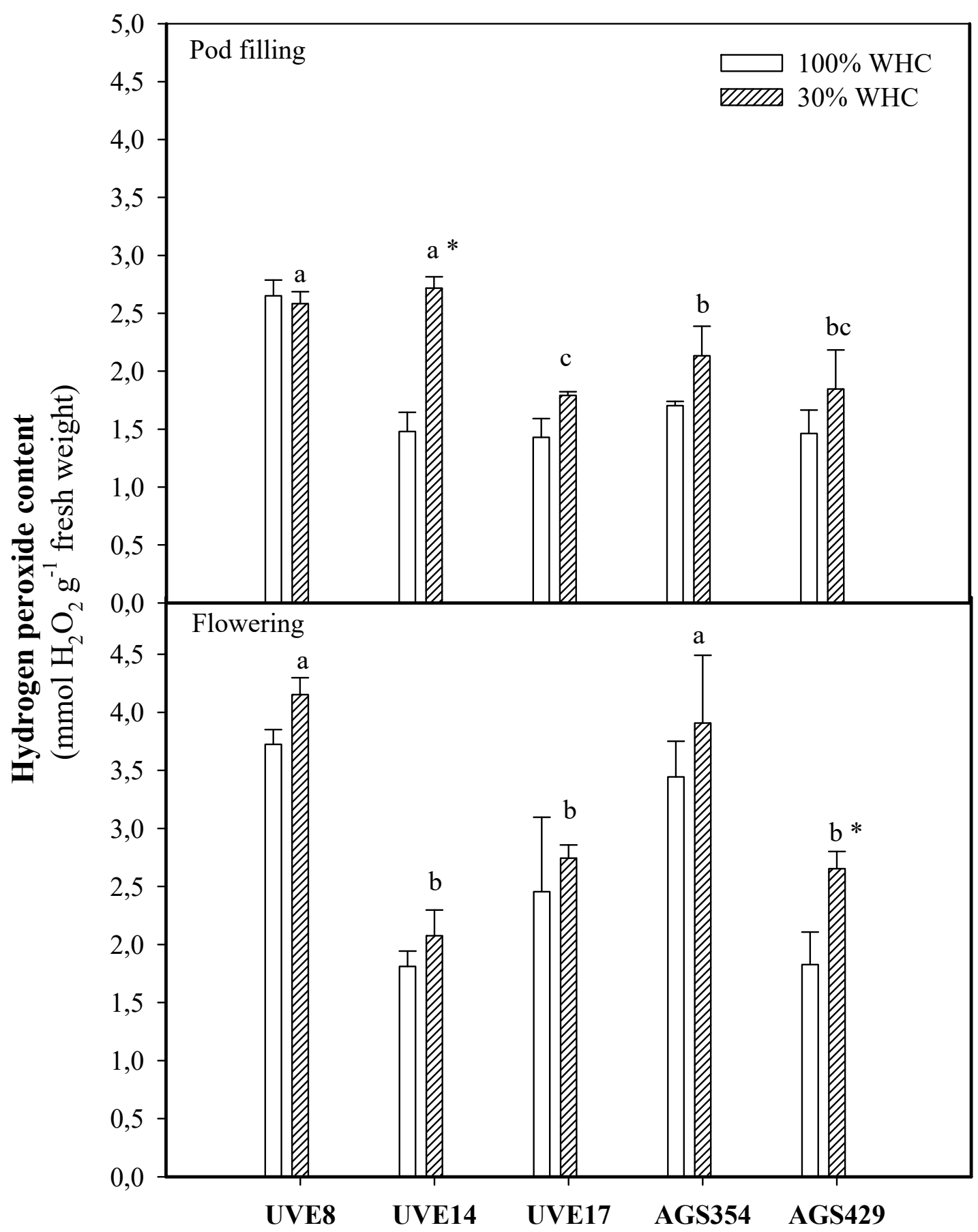

Figure 4. Hydrogen peroxide contents for five vegetable-type soybean cultivars subjected to two water treatments at flowering and pod-filling stages. Values represent means $\pm \mathrm{SD}(n=3)$. Letters represent significant differences/similarities in $\mathrm{H}_{2} \mathrm{O}_{2}$ content for various cultivars under severe water stress at $30 \%$ water holding capacity (WHC), ${ }^{*}$ represents significance at $p \leq 0.05$.

Drought stress induced a substantial increase in the APX activity of UVE17 (47\%) and AGS429 (60\%) at flowering. AGS429 was significantly high and different from the other cultivars for this parameter under drought stress at flowering. At pod filling, there was a significant decrease in the APX activity of UVE8, AGS354, and AGS429 under drought stress, with the highest decrease recorded for AGS354 (76\%). Although not significant, there was a slight increase in the APX activity of UVE14 under drought stress (Figure 5). 


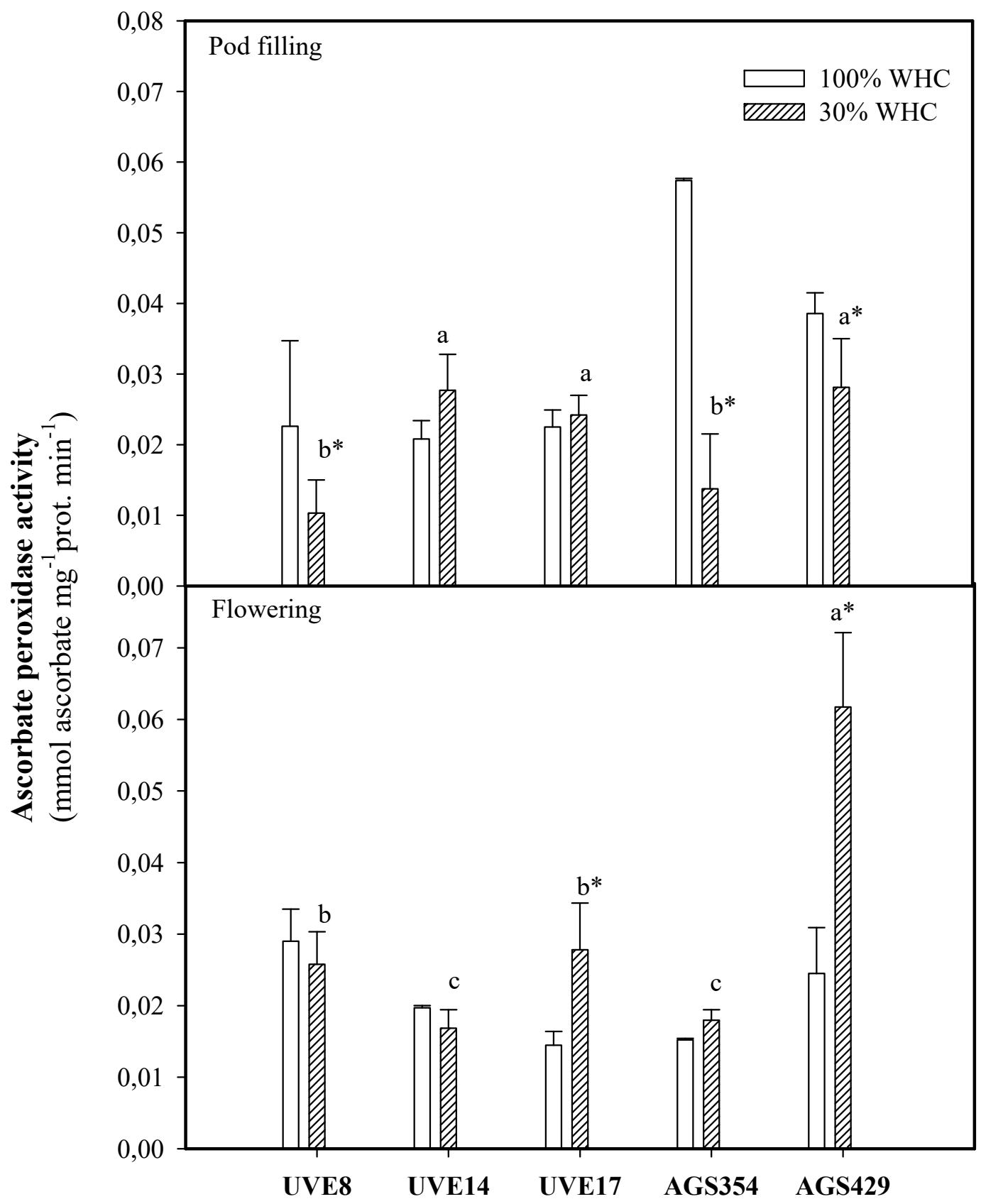

Figure 5. Ascorbate peroxidase (APX) activity for five vegetable-type soybean cultivars subjected to two water treatments at flowering and pod-filling stages. Values represent means $\pm \mathrm{SD}(n=3)$. Letters represent significant differences/similarities in APX activity for various cultivars under severe water stress at $30 \%$ water holding capacity (WHC), * represents significance at $p \leq 0.05$.

There was a significant drop in GPX activity of drought-stressed AGS354 (66\%) at flowering. Contrarily, AGS429 had a substantial increase (45\%) in GPX activity under drought stress. At pod filling, there was a decline in GPX activity under drought stress, where UVE17 and AGS354 recorded significant decreases (74\% and 62\%). Interestingly for AGS429, there was no decrease under drought stress. AGS429 was different from the other cultivars at flowering and pod filling under drought stress (Figure 6). 


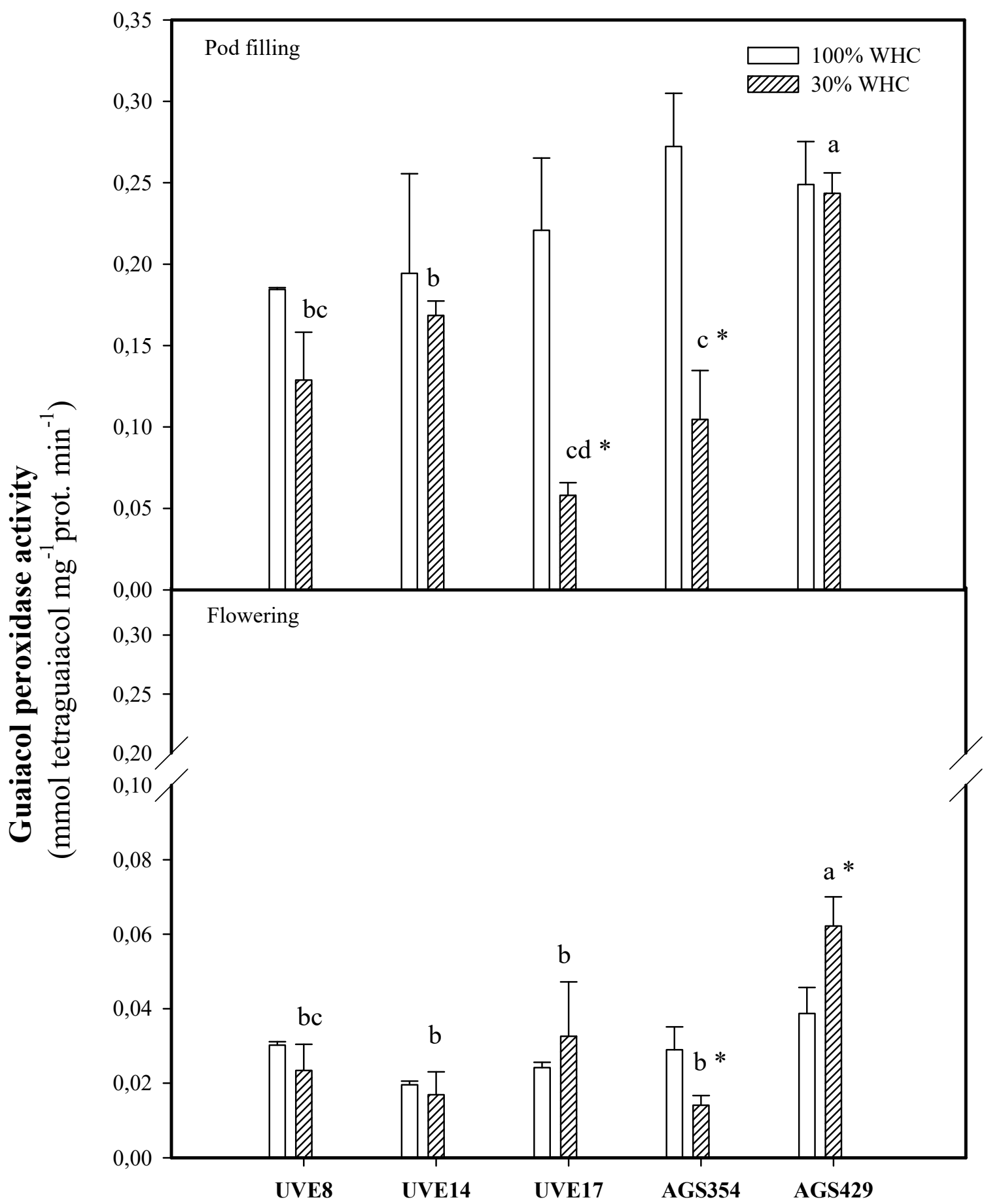

Figure 6. Guaiacol peroxidase (GPX) activity for five vegetable-type soybean cultivars subjected to two water treatments at flowering and pod-filling stages. Values represents means $\pm \mathrm{SD}(n=3)$. Letters represent significant differences/similarities in GPX activity for various cultivars under severe water stress at $30 \%$ water holding capacity (WHC), * represents significance at $p \leq 0.05$.

AGS429 and UVE17 were not different for GR activity at both flowering and pod-filling stages under drought stress. At flowering, drought stress induced substantial increases in the GR activity of UVE17 (70\%) and AGS429 (45\%). At pod filling, a significant increase in GR activity was only for drought-stressed UVE17 (33\%). In contrast to the flowering stage, drought stress substantially reduced the GR activity of AGS429 by 34\% (Figure 7). 


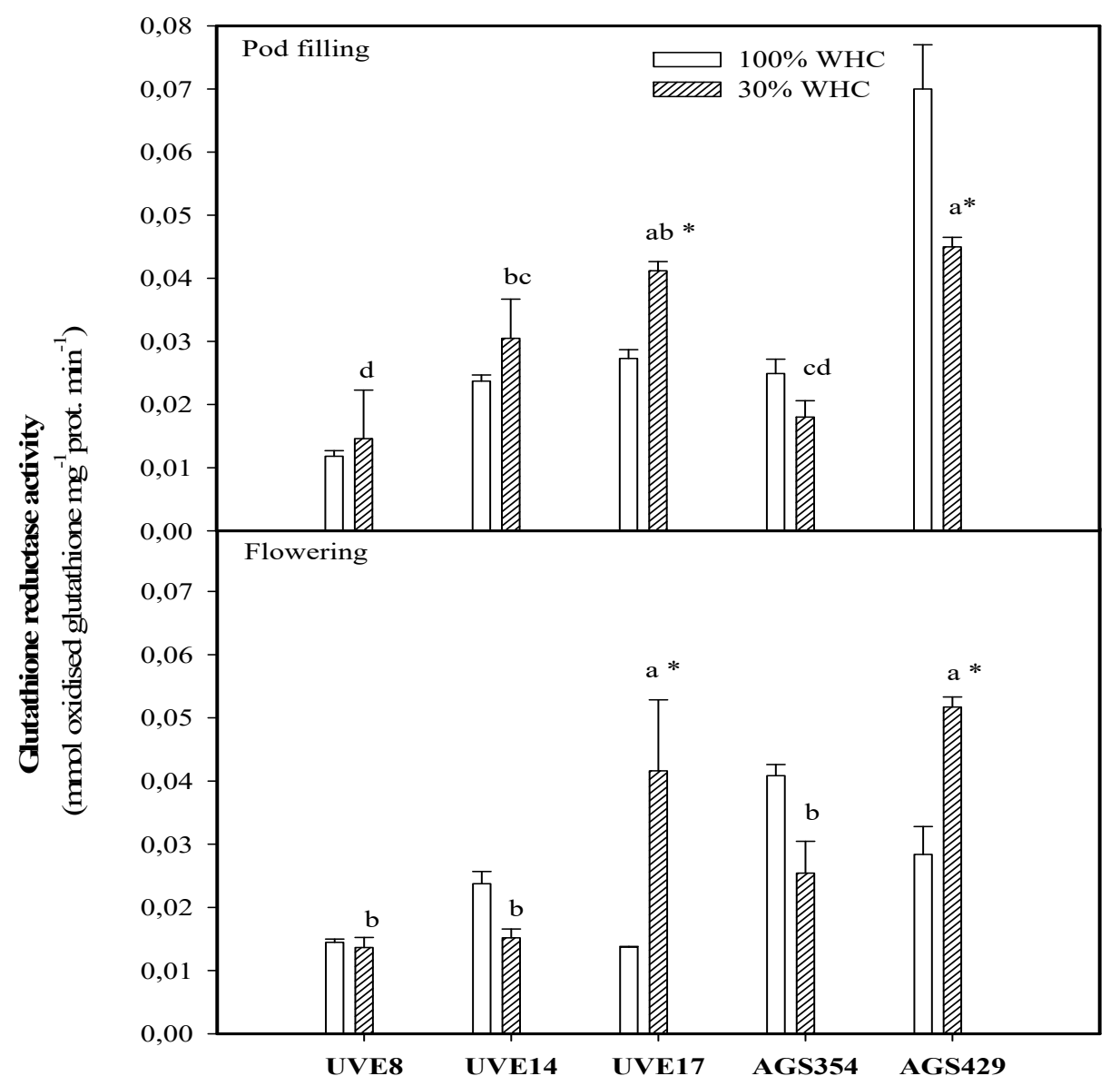

Figure 7. Glutathione reductase (GR) activity for five vegetable-type soybean cultivars subjected to two water treatments at flowering and pod-filling stages. Letters represent significant differences/similarities in GR activity for various cultivars under severe water stress at 30\% water holding capacity (WHC), ${ }^{*}$ represents significance at $p \leq 0.05$.

Correlations between the yield parameters and biochemical responses were analyzed to determine their relationships under drought stress conditions. At flowering, there were highly significant positive correlations $(p \leq 0.01)$ between $\mathrm{H}_{2} \mathrm{O}_{2}$ and TSMP as well as TSP. Additionally, TSS correlated positively with TPP $(p \leq 0.05)$. At pod filling, there was a significant but negative correlation between APX and TSMP and TSP $(p \leq 0.05)$. Likewise, GR was negatively correlated to these parameters in a significant manner. There was a noteworthy positive correlation between $\mathrm{H}_{2} \mathrm{O}_{2}$ and TSP $(p \leq 0.05)$. Proline was significantly correlated with TSP (Table 2).

Table 2. Correlations between the biochemical and yield parameters for five vegetable-type soybean cultivars subjected to severe drought stress at flowering and pod-filling stages.

\begin{tabular}{ccccccccc}
\hline & Flowering & \multicolumn{5}{c}{ Pod Filling } \\
\hline & 100 SM & TPP & TSMP & TSP & 100 SM & TPP & TSMP & TSP \\
\hline APX & -0.2215 & 0.4857 & -0.1685 & -0.0100 & 0.2132 & 0.1394 & $-0.5640^{*}$ & $-0.5636^{*}$ \\
GPX & -0.2366 & 0.4414 & -0.2385 & -0.0793 & 0.1640 & 0.2178 & -0.0132 & 0.0906 \\
$\mathrm{GR}$ & -0.3062 & 0.2359 & -0.4766 & -0.4130 & 0.0942 & -0.0336 & $-0.6558^{* *}$ & $-0.6194^{*}$ \\
$\mathrm{H}_{2} \mathrm{O}_{2}$ & -0.0122 & 0.4852 & $0.7846^{* *}$ & $0.6993 * *$ & -0.0812 & 0.0417 & 0.4724 & $0.5615^{*}$ \\
$\mathrm{MDA}$ & 0.3020 & 0.3745 & 0.7146 & 0.4747 & -0.1244 & 0.0167 & 0.0489 & 0.1078 \\
Proline & -0.3315 & -0.2202 & 0.0749 & 0.2004 & 0.0111 & 0.2079 & 0.4955 & $0.6217^{*}$ \\
TSS & 0.0541 & $0.515^{*}$ & 0.4012 & 0.3894 & 0.2382 & 0.4506 & 0.4900 & 0.4846 \\
\hline
\end{tabular}

${ }^{*} p \leq 0.05,{ }^{* *} p \leq 0.01$. APX $=$ ascorbate peroxidase, $\mathrm{GPX}=$ guaiacol peroxidase, $\mathrm{GR}=$ glutathione reductase, $\mathrm{H}_{2} \mathrm{O}_{2}=$ hydrogen peroxide, $\mathrm{MDA}=$ malondialdehyde, $\mathrm{TSS}=$ total soluble sugars, $100 \mathrm{SM}=100$ seed mass, $\mathrm{TPP}=$ total pods per plant, $\mathrm{TSMP}=$ total seed mass per plant, and TSP = total seeds per plant. 
Out of the 11 principal components (PCs), PC1 and PC2 explained $76.12 \%$ of the total variation for cultivars under severe drought stress during flowering. Parameters that showed positive loadings with $\mathrm{PC} 1$ were $\mathrm{H}_{2} \mathrm{O}_{2}$, MDA, TPP, TSMP, TSS, and TSP. The positive associations among the parameters were in accordance with results from Table 2, where significant positive correlations were observed between $\mathrm{H}_{2} \mathrm{O}_{2}$ with TSMP and TSP, respectively, and between TSS and TPP. At pod filling, PC1 and PC2 explained $73.09 \%$ of the total variation under severe stress. Parameters that showed positive loadings with PC1 were $\mathrm{H}_{2} \mathrm{O}_{2}$, proline, TSMP, TSS, and TSP. From these parameters, only TSP showed significant positive correlations with $\mathrm{H}_{2} \mathrm{O}_{2}$ and proline, respectively (Table 2). However, TSMP and TSP, which showed positive loadings in PC1, were significantly and negatively correlated with APX and GR, which showed negative loadings in PC1.

Results from the PCA biplots confirmed the variability among cultivars in response to the biochemical parameters under severe drought stress. At flowering, cultivar AGS429 showed the highest production for TSS, APX, GPX, and GR, while cultivar AGS354 had the highest significant contents of MDA and $\mathrm{H}_{2} \mathrm{O}_{2}$ (Figure 8).

\section{Principal components biplot $(76.12 \%)$}

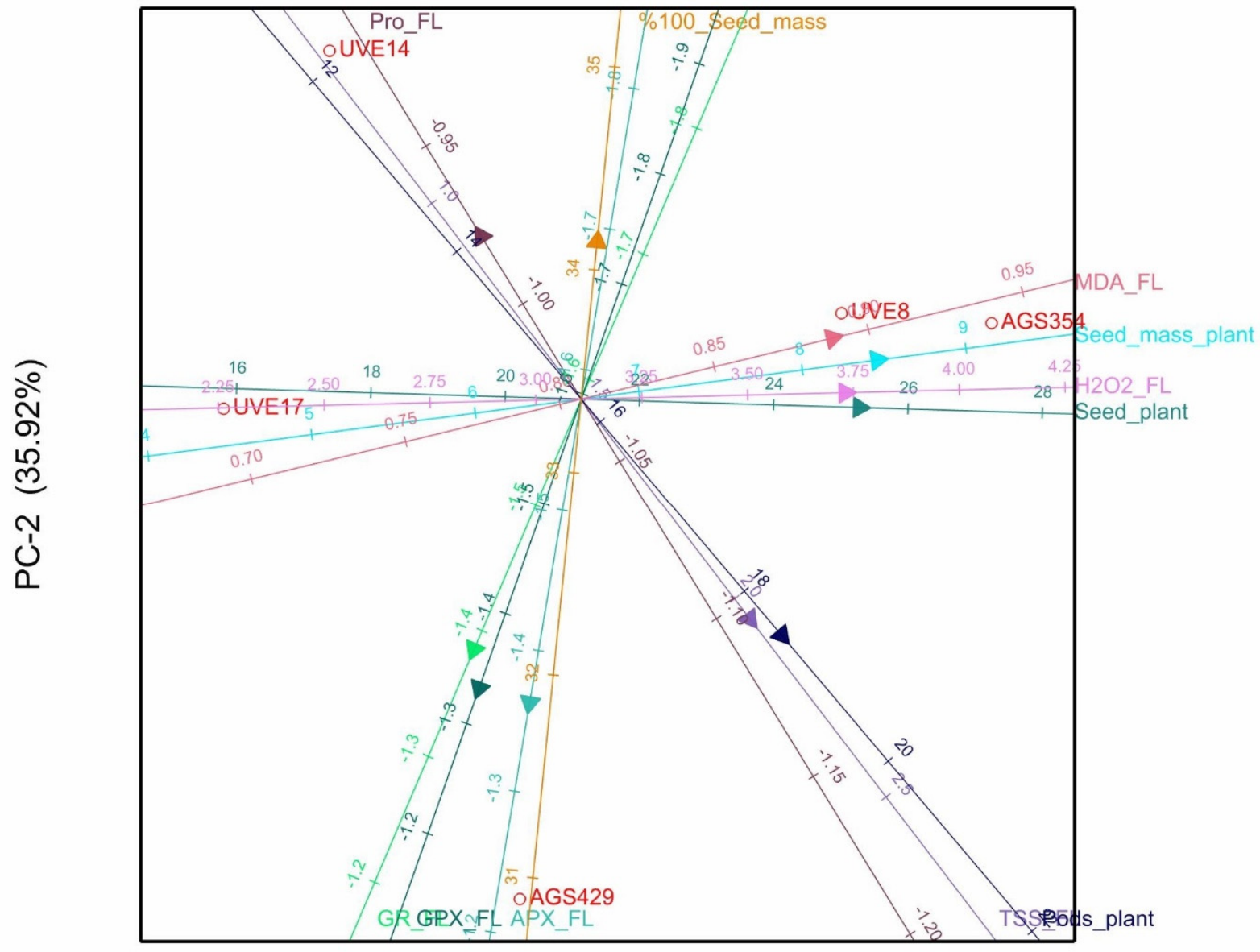

PC-1 (40.2\%)

Figure 8. Principal components biplot between PC1 and PC2 showing the contribution of biochemical and yield parameters to the variability of five vegetable-type soybean cultivars subjected to severe stress at flowering.

At pod filling, cultivar UVE8 showed the highest production of proline, TSS, and $\mathrm{H}_{2} \mathrm{O}_{2}$, while it showed lower production of APX and GPX. Cultivar AGS429 had the highest production of GPX and GR, with the lowest production of MDA content (Figure 9). 


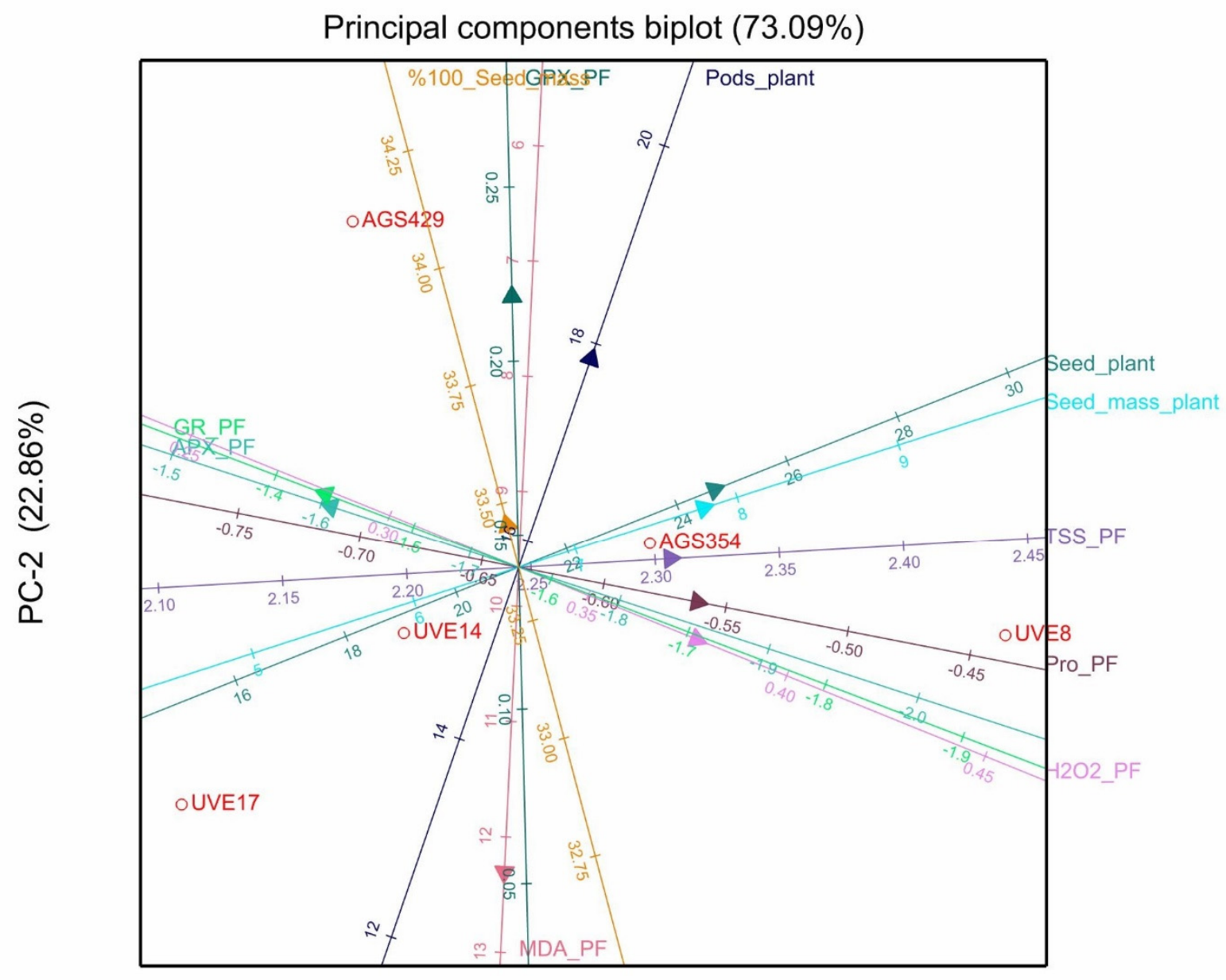

PC-1 $(50.23 \%)$

Figure 9. Principal components biplot between PC1 and PC2 showing the contribution of biochemical and yield parameters to the variability of five vegetable-type soybean cultivars subjected to severe stress at pod filling.

\section{Discussion}

Changing climatic conditions, such as increases in drought occurrences globally, are detrimental to crop growth and production because they hinder plant metabolic functions [12]. Proline often plays an important osmoregulation role, especially during drought stress [1]. Moreover, it can also act as an antioxidant in plants, thereby preventing oxidative stress and stabilizing cell membranes [13]. In peanuts, drought tolerance was associated with a high accumulation of proline biosynthesis [14]. Similarly, increased proline accumulation corresponded to less reduction in the relative water content and shoot and root fresh/dry weight in Indian grain soybean cultivars exposed to mild water stress [15]. Contrarily, our study shows that drought stress does not affect proline accumulation for all cultivars at flowering. It was only at pod filling that drought stress induced a significant increase in proline accumulation, which was selective for AGS429 (Figure 1). This agrees with a review by Mwenye et al. [16], who showed that genotypic variations in proline accumulation exist in soybeans. In addition, higher proline accumulation at pod filling shows that its induction under drought stress is specific for AGS429 at this growth stage, which is in agreement with findings that a plant's response to drought stress varies with species and developmental stage [6]. Based on the significant positive correlation between proline at pod filling and total seeds per plant (TSP) (Table 2), it is evident that upregulation of proline accumulation at this stage could be crucial for some of the drought tolerance responses of vegetable-type soybean. AGS429 is a stable cultivar with low yield reduction 
under drought stress [17]. Therefore, induction of proline during drought stress suggests its importance in the drought tolerance of vegetable-type soybean.

The non-structured sugars formed during photosynthesis are the primary sources of translocated and partitioned carbon in plants. Since drought stress affects the photosynthesis process negatively, it is common for plants to adjust their accumulation of soluble sugars (Nishizawa et al. 2008, as cited by [18]). The current study shows that cultivars reacted differently when it comes to total soluble sugars (TSS). Drought stress induced a high accumulation of TSS in AGS429 at flowering and pod filling, while it was significantly high only at pod filling for UVE14 (a stable cultivar under severe drought stress) (Figure 2). These findings suggest the involvement of TSS in the drought tolerance responses of vegetable-type soybean, probably in osmoregulation, stabilizing biomolecules and cell membranes [19] and preventing oxidative damage (Rolland et al. 2006, as cited by $[18,20])$. A significant relationship between TSS and total pods per plant (TPP) at flowering ( $p \leq 0.05$; Table 2, Figure 8$)$ and a further strong association between these parameters at pod filling (Figure 9) show that non-structured sugars are highly significant for the induction of the drought tolerance responses in vegetable-type soybeans. Similar to proline, it appears that TSS content increased with the reproductive stages.

Like many environmental stresses, drought stress induces the overproduction of reactive oxygen species (ROS), leading to oxidative stress. This condition is harmful to plants as it can cause damage to biomolecules such as the lipids to the fatty acids of a cell membrane, producing small hydrocarbons such as malondialdehyde (MDA), the final product of lipid peroxidation and a sign of cellular membrane damage [21]. Drought stress induced significantly high MDA accumulation at flowering in AGS354. This suggests that severe drought stress induced oxidative stress in this cultivar, leading to high lipid peroxidation and poor yield performance. A study by van der Merwe et al. [17] supports this suggestion because they showed that AGS354 is a cultivar with a high yield reduction under severe drought stress. A high MDA content in AGS354 further supports this suggestion (Figure 8). Contrarily, the lower MDA content, with an insignificant increase under severe drought stress, in AGS429 (Figure 3) suggests that it has a better mechanism of scavenging ROS, thereby limiting oxidative-stress-related consequences.

High accumulation of $\mathrm{H}_{2} \mathrm{O}_{2}$ in drought-stressed vegetable-type soybean cultivars (Figure 4) confirms that this type of stress induces an accumulation of ROS, which leads to oxidative stress and, consequently, lipid peroxidation. However, a relationship between $\mathrm{H}_{2} \mathrm{O}_{2}$ production and lipid peroxidation under drought stress needs consideration because the responses differ with the developmental stages. For example, at flowering under drought stress, AGS429 had the lowest MDA content, with a significant increase in $\mathrm{H}_{2} \mathrm{O}_{2}$ content (although the level of $\mathrm{H}_{2} \mathrm{O}_{2}$ was lower than that of other cultivars). Contrarily, at pod filling for UVE14, a significant increase in $\mathrm{H}_{2} \mathrm{O}_{2}$ production corresponded to a significant increase in lipid peroxidation. However, the correlation between these two parameters was significant at flowering but not at pod filling (Table 2, Figure 8). Since $\mathrm{H}_{2} \mathrm{O}_{2}$ is positively correlated with total seed mass per plant (TSMP) (Table 2) and total seed per plant (TSP) under drought stress (also confirmed by Figures 8 and 9), which are the essential yield parameters, the results suggest that $\mathrm{H}_{2} \mathrm{O}_{2}$ is a very important biochemical parameter that is involved in the signaling events of vegetable-type soybean drought tolerance responses. However, the production of $\mathrm{H}_{2} \mathrm{O}_{2}$ needs strict control measures to avoid oxidative burst. This agrees with a study by Guler and Pehlivan [22], who reported that exogenous application of $\mathrm{H}_{2} \mathrm{O}_{2}$ at low doses elevates the drought tolerance responses of soybeans. Furthermore, exogenous $\mathrm{H}_{2} \mathrm{O}_{2}$ effectively alleviated oxidative damage in rice seedlings by upregulating the activities of antioxidant enzymes [23]. $\mathrm{H}_{2} \mathrm{O}_{2}$ is a key player in signal transduction pathways associated with abiotic stress when not produced excessively during abiotic stress [24]. Therefore, a threshold for the role of $\mathrm{H}_{2} \mathrm{O}_{2}$ as a signaling molecule in vegetable-type soybean needs to be established.

In order to maintain ROS balance under stress (i.e., to prevent oxidative stress), plants must possess a functional antioxidative system. The above findings on the involvement 
of $\mathrm{H}_{2} \mathrm{O}_{2}$ in the drought tolerance responses of vegetable-type soybean will prompt an understanding of the role of antioxidative enzymes in this regard. Studies of more than a decade ago revealed a positive correlation between drought tolerance and the ROS scavenging capacity of plants [25]. The level of increase or inhibition of antioxidative enzyme activities under drought stress is variable among plant species and even between cultivars of the same species [26]. In grain, soybeans under drought stress have induced ascorbate peroxidase (APX) activity, which serves as a biochemical marker for drought tolerance [11]. In the current study, AGS429 recorded the most significant increase in APX activity at the flowering stage. It appears that the effect varies with cultivars and developmental stages because, at pod filling, APX activity dropped for almost all cultivars under drought stress but not significantly for UVE14 (Figure 5). There was no direct link between APX activity at flowering and the drought tolerance responses (explained by insignificant correlations between APX and the yield parameters; Table 2 and Figure 8).

At pod filling, this relationship was negative (Table 2, Figure 9). This indicates that higher APX activity is required to maintain homeostasis between $\mathrm{H}_{2} \mathrm{O}_{2}$ produced and scavenged, thereby allowing $\mathrm{H}_{2} \mathrm{O}_{2}$ to be involved in the signaling events for induction of drought tolerance responses in vegetable-type soybean. In agreement with this view, the highest decrease in APX activity for AGS354 (which is a highly unstable cultivar) at pod filling associates APX with vegetable-type soybean drought tolerance indirectly. An increase in the guaiacol peroxidase (GPX) activity of AGS429 was selective only for the flowering stage under drought stress. For other cultivars, GPX activity either decreased or was not significant (Figure 6). Supporting this, AGS354 and UVE17, which are susceptible to severe drought, had a huge reduction in GPX activity. Similar to APX, there was no significant difference in the GPX activity of AGS429 at pod filling, which indicates that for this cultivar, GPX is more effective at the flowering stage. This enzyme was not directly associated with any of the yield parameters. Under drought conditions, GR favors the maintenance of the glutathione pool, thereby intensifying the antioxidative response of the plant [27]. Although the glutathione reductase (GR) activity of AGS429 and UVE17 increased due to drought stress (Figure 7), significant but negative relationships between this enzyme and the yield parameters (TSMP and TSP) under drought stress (Table 2, Figures 8 and 9) indicate that it is not directly responsible for the drought tolerance responses of vegetable-type soybean. Rather, along with the other antioxidative enzymes studied, they prevent lipid peroxidation and control $\mathrm{H}_{2} \mathrm{O}_{2}$ production to the level that can stimulate the signaling events leading to drought tolerance in vegetable-type soybean.

\section{Materials and Methods}

\subsection{Plant Material and Experimental Design}

Five vegetable-type soybean (Glycine max L. Merrill) cultivars (UVE8, UVE17, UVE14, AGS354, AGS429) were planted in $9 \mathrm{~L}$ potting bags containing $10 \mathrm{~kg}$ of loamy sandy soil (one plant per pot). In a previous study [17], these cultivars were characterized according to their yield performance. AGS429 is a stable cultivar with low yield reduction under drought stress conditions; AGS354 and UVE8 are top-performing cultivars under optimal conditions but highly unstable under drought stress conditions; UVE14 is not a high yield performer but is stable under drought stress conditions; UVE17 is an unstable cultivar under drought stress conditions. A split-plot randomized complete block design trial with three replications was used. Each replication consisted of five pots. The trial was conducted under controlled environmental conditions $\left(25^{\circ} \mathrm{C}\right.$ day and $18{ }^{\circ} \mathrm{C}$ night $)$ in a greenhouse. Two water treatments, well-watered (at 100\% soil water holding capacity) and severe stress (at 30\% soil water holding capacity), were applied, according to the literature [28,29], at the third trifoliate stage. Pots were weighed daily for accurate water treatments. This was done in conjunction with the use of a Hydrosense II soil moisture sensor fitted with a CS659 $(12 \mathrm{~cm}$ ) portable soil-water probe (Campbell Scientific, Stellenbosch, South Africa) to ascertain the accuracy of the drought stress treatments. Young but fully expanded trifoliate leaves were harvested from each of the five pots per treatment, and this was replicated at 
flowering and pod filling stages. This was done because drought treatment at reproductive stages significantly increases the rate of pod abortion and, consequently, decreases seed yield [30]. The leaves were frozen in liquid nitrogen, combined (from each of the five pots per replication), and crushed in liquid nitrogen to form a homogenous fine powder, followed by storage at $-26^{\circ} \mathrm{C}$.

\subsection{Proline Assay}

A modified method of Carillo and Gobon [31] was used for the proline assay. Ethanol $(4 \mathrm{~mL}) 70 \%(v / v)$ was used to homogenize the leaf powder $(0.3 \mathrm{~g})$ to a fine paste on ice. This step was repeated three times for each replication. The homogenate was centrifuged at $3000 \times g$ for $10 \mathrm{~min}$. Supernatant $(500 \mu \mathrm{L}), 20 \%$ ethanol $(500 \mu \mathrm{L})$, and $1 \%(\mathrm{~m} / v)$ acidic ninhydrin (prepared in $60 \%, v / v$, glacial acetic acid) were vortexed before incubation at $95{ }^{\circ} \mathrm{C}$ for $20 \mathrm{~min}$. After cooling, samples were centrifuged at $10,000 \times \mathrm{g}$ for $10 \mathrm{~min}$. The absorbance of the samples was measured at $520 \mathrm{~nm}$ (Cary 100 Bio, Varian, Australia) against a blank. A serial dilution of $0.016-0.16 \mathrm{mM}$ proline (in 70\% ethanol) was prepared and subjected to similar steps.

\subsection{Total Soluble Sugars Assay}

Determination of total soluble sugars (TSS) was done according to a method described by Irigoyen et al. [32]. Frozen leaf powder $(0.1 \mathrm{~g})$ was homogenized in $96 \%(v / v)$ ethanol, followed by incubation $\left(80^{\circ} \mathrm{C}, 10 \mathrm{~min}\right)$ and centrifugation $\left(4000 \times \mathrm{g}, 10 \mathrm{~min}, 4^{\circ} \mathrm{C}\right)$. This procedure was repeated three times for each replication. Ethanoic extract $(50 \mu \mathrm{L})$ was added to $1450 \mu \mathrm{L}$ anthrone reagent $\left(1.5 \mathrm{mg} \mathrm{mL}^{-1}\right)$ prepared in $72 \%(v / v)$ sulphuric acid. The mixture was vortexed vigorously and incubated at $80{ }^{\circ} \mathrm{C}$ for $15 \mathrm{~min}$. Absorbance was measured spectrophotometrically at $625 \mathrm{~nm}$ (Cary 100 Bio, Varian, Australia). The estimation of TSS was calculated from a glucose standard.

\subsection{Lipid Peroxidation}

Lipid peroxidation was done by measuring its by-product, malondialdehyde (MDA). The assay was done according to a modified method of Heath and Packer [33]. Leaf powder was homogenized in $5 \mathrm{~mL} \mathrm{20 \%}(\mathrm{m} / \mathrm{v})$ trichloroacetic acid (TCA) and centrifuged $(3500 \times g)$ for $20 \mathrm{~min}$ at $4{ }^{\circ} \mathrm{C}$. This procedure was repeated three times for each replication. To $1 \mathrm{~mL}$ aliquot, $1 \mathrm{~mL} \mathrm{20 \%} \mathrm{(TCA)} \mathrm{containing} 0.5 \%$ thiobarbituric acid (TBA) was added. The mixture was vortexed, followed by incubation at $95^{\circ} \mathrm{C}$ for $30 \mathrm{~min}$. After cooling, the absorbance of the MDA-TBA product was measured spectrophotometrically at 532 and $600 \mathrm{~nm}$ (Cary 100 Bio, Varian, Australia). An extinction coefficient of $155 \mathrm{mM}^{-1} \mathrm{~cm}^{-1}$ was used to calculate the MDA content.

\subsection{Hydrogen Peroxide Assay}

A modified method described by Velikova et al. [34] was used for hydrogen peroxide $\left(\mathrm{H}_{2} \mathrm{O}_{2}\right)$ content determination. To the frozen leaf powder $(300 \mathrm{mg}), 2 \mathrm{~mL}$ of ice-cold $0.1 \%$ trichloroacetic acid (TCA) $(w / v)$ was added, homogenized, and centrifuged $(12,000 \times g)$ for $15 \mathrm{~min}$ at $4{ }^{\circ} \mathrm{C}$. This procedure was repeated three times for each replication. To the supernatant $(0.5 \mathrm{~mL}), 0.5 \mathrm{~mL} 10 \mathrm{mM}$ potassium phosphate buffer $(\mathrm{pH} 7.0)$ and $1 \mathrm{~mL}$ $1 \mathrm{M}$ potassium iodide were added. For the blank, $0.1 \%$ TCA was used. Absorbance was measured at $390 \mathrm{~nm}$ (Cary 100 Bio, Varian, Australia). The $\mathrm{H}_{2} \mathrm{O}_{2}$ standard was subjected to similar conditions.

\subsection{Enzyme Extract Preparation}

Enzyme extracts were prepared in accordance with Pukacka and Ratajczak [35]. Leaf powder $(0.5 \mathrm{~g})$ for each treatment was homogenized to a fine paste on ice using a mortar and pestle in $5 \mathrm{~mL} 50 \mathrm{mM}$ potassium phosphate buffer ( $\mathrm{pH}$ 7.0) containing $1 \mathrm{mM}$ EDTA, $2 \%$ PVPP, $0.1 \%$ Triton $\mathrm{X}-100$, and $1 \mathrm{mM}$ ascorbate. This procedure was repeated three times 
for each replication. The homogenate was centrifuged at $15,000 \times g$ for $20 \mathrm{~min}$ at $4{ }^{\circ} \mathrm{C}$. The resulting aliquot was used as the enzyme extract.

\subsection{Enzyme Assays and Protein Content}

The APX assay was performed according to a method described by Mishra et al. [36], with modifications. The reaction mixture $(1 \mathrm{~mL})$ consisted of $500 \mu \mathrm{L} 50 \mathrm{mM}$ phosphate buffer (pH 7.0), $200 \mu \mathrm{L} 0.1 \mathrm{mM} \mathrm{H}_{2} \mathrm{O}_{2}, 150 \mu \mathrm{L} 0.5 \mathrm{mM}$ sodium ascorbate, $50 \mu \mathrm{L} 0.1 \mathrm{mM}$ EDTA, and $100 \mu \mathrm{L}$ enzyme. A decrease in absorbance as a result of ascorbate oxidation was measured at $290 \mathrm{~nm}$ (Cary $100 \mathrm{Bio}$, Varian, Australia) for 5 min at $20{ }^{\circ} \mathrm{C}$ against a blank in which the enzyme was replaced with phosphate buffer. An extinction coefficient of $2.8 \mathrm{mM}^{-1} \mathrm{~cm}^{-1}$ was used to calculate enzyme activity.

A modified method described by Zieslin and Ben-Zaken [37] was used for the determination of GPX. The reaction mixture contained $50 \mu \mathrm{L} 0.2 \mathrm{M} \mathrm{H}_{2} \mathrm{O}_{2}, 100 \mu \mathrm{L} 50 \mathrm{mM}$ guaiacol, $340 \mu \mathrm{L}$ distilled $\mathrm{H}_{2} \mathrm{O}, 500 \mu \mathrm{L} 80 \mathrm{mM}$ phosphate buffer ( $\mathrm{pH}$ 5.5), and 10 enzymes. An increase in absorbance as a result of tetraguaiacol formation was measured at $470 \mathrm{~nm}$ (Cary 100 Bio, Varian, Australia) for $3 \mathrm{~min}$ at $30^{\circ} \mathrm{C}$. The blank contained all reagents except for the enzyme, which was replaced with phosphate buffer. An extinction coefficient of $26.6 \mathrm{mM}^{-1} \mathrm{~cm}^{-1}$ was used to calculate enzyme activity.

Protein concentration determination was done according to Bradford [38] using $\gamma$ globulin as a standard in order to calculate specific enzyme activities.

\subsection{Yield Parameters}

Yield traits (100 seed mass, total pods per plant, total seeds per plant, and total seed mass per plant) were measured at the end of the trial when the plants reached maturity (at the R8 growth stage). They were measured only to establish their relationships with the investigated biochemical responses, which better provide information for drought tolerance in vegetable-type soybean. The reason for not presenting them as part of this study is that a detailed study on how drought (severe and mild) affects these cultivars is already available [17].

\subsection{Statistical Analysis}

Data collected on all biochemical and yield parameters evaluated in this study were subjected to analysis of variance (ANOVA) in order to determine the separate and combined effects of cultivars and water treatments. A test for normality was done using the ShapiroWilk test. Where skewness in data was detected, data transformation was done using logarithmic $(\log 10)$ transformation. Where significant effects in the ANOVA were detected, Fisher's protected least significant difference (LSD) test at $p=0.05$ was used to separate the means. Correlation analysis was performed to determine relationships between the biochemical and yield parameters. Principal component analysis (PCA) was performed to visualize associations between the parameters as well as genotype associations with the parameters. The PCA loadings biplot is a plot of the direction of vectors that define the model. They show how the original variables (the parameters in this study) contribute to creating the principal component (PC). The biplot shows the original parameters as vectors (colored lines). Orientation of the vector is indicated by the arrow, which further indicates the direction of the most variation and contribution to the respective PC. The angles between vectors of different parameters show their correlation in this space. For example, an acute angle between vectors represents a high positive correlation, a right angle represents a lack of correlation, and obtuse angles represent high negative correlations. All statistical analyses were performed using Genstat Release 19 software [39].

\section{Conclusions}

The levels of all biochemical responses (except $\mathrm{H}_{2} \mathrm{O}_{2}$ ) increased with the developmental stage in drought-stressed vegetable-type soybean. This study shows that total soluble sugars (TSS) at flowering and proline at pod filling are important to the drought toler- 
ance responses of vegetable-type soybean. This prompts further investigations to identify specific non-structured sugars that are essential for drought tolerance improvements in this crop. Although the activities of the antioxidative enzymes increased under drought stress at both developmental stages in the drought-stable vegetable-type soybean cultivars (AG429 and UVE14), they are indirectly associated with drought tolerance because of their negative relationships with the yield parameters. This study suggests that they function in concert to minimize (but not completely eradicate) the excessive production of $\mathrm{H}_{2} \mathrm{O}_{2}$, thereby preventing excessive lipid peroxidation and membrane damage. A controlled increase in $\mathrm{H}_{2} \mathrm{O}_{2}$ production at both developmental stages under severe drought stress is crucial for the signaling events leading to an induction of the yield parameters, total seed mass per plant (TSMP) and total seed per plant (TSP), in vegetable-type soybean. A threshold for $\mathrm{H}_{2} \mathrm{O}_{2}$ to act as a signal molecule under drought stress in vegetable-type soybean needs thorough investigation because values between 3.09 and $4.14 \mathrm{mmol} \mathrm{H}_{2} \mathrm{O}_{2} \mathrm{~g}^{-1}$ fresh mass (in AGS354 and UVE8, respectively) promoted the highest lipid peroxidation, while lower values ( $2.65 \mathrm{mmol} \mathrm{H}_{2} \mathrm{O}_{2} \mathrm{~g}^{-1}$ fresh mass) seemed to stimulate signaling events. When thoroughly studied, such information could be useful for the application of low doses of peroxide for possible improvement of vegetable-type soybean production under severe drought stress. Although this study was performed in South Africa, it is applicable to the improvement of vegetable-type soybean drought tolerance globally.

Author Contributions: Conceptualization, methodology, investigation, writing-original draft preparation, project administration, funding acquisition, M.J.M.; trial design, statistical analysis, writing-editing, R.v.d.M. Both authors have read and agreed to the published version of the manuscript.

Funding: This research was funded by the National Research Foundation's Thuthuka program (grant number TTK180502325292) and the University of the Free State.

Acknowledgments: We thank the Edamame Development Program (EDP) for providing the original seed material and Sisanda Mathabo Zungu for assisting with the trials.

Conflicts of Interest: The authors declare no conflict of interest.

\section{References}

1. Farooq, M.; Wahid, A.; Kobayashi, N.; Fujita, D.; Basra, S.M.A. Plant drought stress: Effects, mechanism and management. Agron. Sustain. Dev. 2009, 29, 185-212. [CrossRef]

2. Basal, O.; Szabo, A. Physiology yield and quality of soybean as affected by drought stress. Asian J. Agric. Biol. $2020,3,247-253$. [CrossRef]

3. Djanta, M.K.A.; Agoyi1, E.E.; Agbahoungba1, S.; Quenum, F.J.-B.; Chadare, F.J.; Assogbadjo, A.E.; Agbangla, C.; Sinsin, B. Vegetable soybean, edamame: Research, production, utilization and analysis of its adoption in Sub-Saharan Africa. J. Hort. For. 2020, 12, 1-12.

4. Masuda, T.; Goldsmith, P.D. World Soybean Production: Area harvested, yield, and long-term projections. Int. Food Agribus. Manag. Rev. 2009, 12, 143-162.

5. Ceccherini, G.; Russo, S.; Ameztoy, I.; Marchese, A.F.; Carmona-Moreno, C. Heat waves in Africa 1981-2015, observations and reanalysis. Nat. Hazards Earth Syst. Sci. 2017, 17, 115-125. [CrossRef]

6. Demirevska, K.; Zasheva, D.; Dimitrov, R.; Simova-Stoilova, L.; Stamenova, M.; Feller, U. Drought stress effects on Rubisco in wheat: Changes in the Rubisco large subunit. Acta Physiol. Plant 2009, 31, 1129-1138. [CrossRef]

7. Fahad, S.; Bajwa, A.A.; Nazir, U.; Anjum, A.S.; Farooq, A.; Zohaib, A.; Sadia, S.; Nasim, W.; Adkins, S.; Saud, S.; et al. Crop production under drought and heat stress: Plant responses and management options. Front. Plant Sci. 2017, 8, 1-16. [CrossRef]

8. Arora, A.; Sairam, R.K.; Sriuastava, G.C. Oxidative stress and antioxidative system in plants. Curr. Sci. 2002, 82, 1227-1238.

9. Xu, P.L.; Guo, Y.K.; Bai, J.G.; Shang, L.; Wang, X.J. Effects of long-term chilling on the ultrastructure and antioxidative activity in leaves of two cucumber cultivars under low light. Physiol. Plant 2008, 132, 467-478. [CrossRef]

10. Mwenye, O.J. Root Properties and Proline as Possible Indicators for Drought Tolerance in Soybean. Ph.D. Thesis, University of the Free State, Bloemfontein, South Africa, 2018.

11. Moloi, M.J.; Mwenye, O.J.; van der Merwe, R. Differential involvement of ascorbate and Guaiacol peroxidases in soybean drought resistance. S. Afr. J. Sci. 2016, 112, 1-4. [CrossRef]

12. Jaleel, C.A.; Manivannan, P.; Wahid, A.; Farooq, M.; Al-Juburi, H.J.; Somasundaram, R.; Vam, R.P. Drought stress in plants: A review on morphological characteristics and pigments composition. Int. J. Agric. Biol. 2009, 11, 100-105.

13. Hayat, S.; Hayat, Q.; Alyemeni, M.A.; Wani, A.S.; Pichtel, J.; Ahmad, A. Role of proline under changing environments. Plant Signal. Behav. 2012, 7, 1456-1466. [CrossRef] [PubMed] 
14. Furlan, A.L.; Bianucci, E.; Giordano, W.; Castro, S.; Becker, D.F. Proline metabolic dynamics and implications in drought tolerance of peanut plants. Plant Physiol. Biochem. 2020, 151, 566-578. [CrossRef] [PubMed]

15. Devi, M.K.A.; Giridhar, P. Variations in Physiological Response, Lipid Peroxidation, Antioxidant Enzyme Activities, Proline and Isoflavones Content in Soybean Varieties Subjected to Drought Stress. Proc. Natl. Acad. Sci. USA India Sect. B Biol. Sci. 2015, 85, 35-44. [CrossRef]

16. Mwenye, O.J.; van Rensburg, L.; van Biljon, A.; van der Merwe, R. The role of proline and root traits on selection for drought-stress tolerance in soybeans: A review. S. Afr. J. Plant Soil 2016, 33, 245-255. [CrossRef]

17. Van der Merwe, R.; Tyawana, S.; Van der Merwe, J.; Mwenye, O. Evaluation of drought tolerance indices in vegetable-type soybean. Mol. Soc. Cient Gal. 2018, 18, 19-31.

18. Andrade, E.R.; Ribeiro, V.N.; Azevendo, C.V.G.; Chiorato, A.F.; Williams, T.C.R.; Carbonell, S.A.M. Biochemical indicators of drought tolerance in common bean (Phaseolus vulgaris L.). Euphytica 2016, 210, 277-289. [CrossRef]

19. Farahat, M.; Ibrahim, M.M.S.; Taha, L.S.; El- Quesni, E.M.F. Response of vegetative growth and some chemical constituents of Cupressuss empervirens L. to foliar application of ascorbic acid and zinc at Nubaria. World J. Agric. Sci. 2007, 3, $282-288$.

20. Cramer, G.R.; Ergul, A.; Grimplet, J.; Tillett, R.L.; Tattersall, E.A.; Bohlman, M.C.; Vincent, D.; Sonderegger, J.; Evans, J.; Osborne, C.; et al. Water and salinity stress in grapevines: Early and late changes in transcript and metabolite profiles. Funct. Integr. Genom. 2007, 7, 111-134. [CrossRef]

21. Cunhua, S.; Wei, D.; Xiangling, C.; Xinna, X.; Yahong, Z.; Dong, S.; Jianjie, S. The effects of drought stress on the activity of acid phosphatase and its protective enzymes in pigweed leaves. Afr. J. Biotech. 2010, 9, 825-833.

22. Guler, N.S.; Pehlivan, N. Exogenous Low-Dose Hydrogen Peroxide Enhances Drought Tolerance of Soybean (Glycine Max L.) through Inducing Antioxidant System. Biol. Fut. 2016, 67, 169-183.

23. Sohag, A.A.M.; Tahjib-Ul-Arif, M.; Brestic, M.; Afrin, S.; Sakil, M.A.; Hossain, M.T.; Hossain, M.A.; Hossain, M.A. Exogenous salicylic acid and hydrogen peroxide attenuate drought stress in rice. Plant Soil Environ. 2020, 66, 7-13. [CrossRef]

24. Hossain, M.A.; Bhattacharjee, S.; Armin, S.M.; Qian, P.; Xin, W.; Li, H.Y.; Burritt, D.J.; Fujita, M.; Tran, L.S.P. Hydrogen peroxide priming modulates abiotic oxidative stress tolerance: Insights from ROS detoxification and scavenging. Front. Plant Sci. 2015, 6, 1-19. [CrossRef]

25. Selote, D.S.; Khanna-Chopra, R. Drought-induced spikelet sterility is associated with an inefficient antioxidant defense in rice panicles. Plant Physiol. 2004, 121, 462-471. [CrossRef]

26. Cruz de Carvalho, M.H. Drought stress and reactive oxygen species. Plant Signal. Behav. 2008, 3, 156-165. [CrossRef] [PubMed]

27. Ünyayar, S.; Çekiç, F.Ö. Changes in antioxidative enzymes of young and mature leaves of tomato seedlings under drought stress. Turk. J. Biol. 2006, 29, 211-216.

28. Karam, F.; Masaad, R.; Sfeir, T.; Mouzer, O.; Rouphael, Y. Evapotranspiration and seed yield of field grown soybean under deficit irrigation conditions. Agric. Water Manag. 2005, 75, 226-244. [CrossRef]

29. Dogan, E.; Kirnak, H.; Copur, O. Deficit irrigations during soybean reproductive stages and CROPGRO-soybean simulations under semi-arid climatic conditions. Field Crop Res. 2007, 103, 154-159. [CrossRef]

30. Westgate, M.E.; Peterson, C.M. Flower and pod development in water-deficient soybean (Glycine max L. Merr.). J. Exp. Bot 1993, 258, 109-117. [CrossRef]

31. Carill0, P.; Gibon, Y. Protocol: Extraction and Determination of Proline. 2011. Available online: https:/ / www.researchgate.net/ publication/211353600_Protocol_Extraction_and_determination_of_proline (accessed on 3 March 2020).

32. Irigoyen, J.J.; Einerich, D.W.; Sánchez-Díaz, M. Water stress-induced changes in concentrations of proline and total soluble sugars in nodulated alfalfa (Medicago sativa) plants. Physiol. Plant 1992, 84, 55-60. [CrossRef]

33. Heath, R.L.; Packer, L. Photoperoxidation in isolated chloroplasts. I. Kinetics and stoichiometry of fatty acid peroxidation. Arch Biochem. Biophys. 1968, 125, 189-198. [CrossRef]

34. Velikova, V.; Yordanov, I.; Edreva, A. Oxidative stress and some antioxidant systems in acid rain-treated bean plants. Protective role of exogenous polyamines. Plant Sci. 2000, 151, 59-66. [CrossRef]

35. Pukacka, S.; Ratajczak, E. Production and scavenging of reactive oxygen species in Fagus sylvatica seeds during storage at varied temperature and humidity. J. Plant Physiol. 2005, 162, 873-885. [CrossRef] [PubMed]

36. Mishra, N.P.; Mishra, R.K.; Singhal, G.S. Changes in the activities of antioxidant enzymes during exposure of intact wheat leaves to strong visible light at different temperatures in the presence of protein synthesis inhibitors. Plant Physiol. 1993, 102, 903-910. [CrossRef] [PubMed]

37. Zieslin, N.; Ben-Zaken, R. Peroxidase, phenylalanine ammonia-lyase and lignification in peduncles of rose flowers. Plant Physiol. Biochem. 1991, 29, 147-151.

38. Bradford, M.M. A rapid and sensitive method for the quantitation of microgram quantities of protein utilizing the principle of protein-dye binding. Anal. Biochem. 1976, 72, 248-254. [CrossRef]

39. VSN International. Genstat for Windows, 19th ed.; VSN International: Hemel Hempstead, UK, 2017. 